\title{
Comparative Evaluation of the Marginal Adaptation of Cast Ni-Cr Copings, Direct Metal Laser Sintering Co-Cr Copings, and Computer- aided Design and Computer-aided Manufacturing Zr Copings: An In-vitro Study
}

Lokanathanbalaji Doddy ${ }^{1}$, Sesha Reddy ${ }^{1}$, Sashideepth Reddy ${ }^{1}$, Narendra R ${ }^{1}$

1. Prosthodontics, Government Dental College and Hospital, Kadapa, IND

Corresponding author: Lokanathanbalaji Doddy, dlokanathanbalajidoddy@gmail.com

\section{Abstract \\ Background and purpose}

Marginal adaptation is critical for the long-term longevity and clinical success of dental restorations. Improper marginal adaptation may lead to oral fluids, resulting in microleakage and cement dissolution. The present in vitro study aimed to evaluate the marginal adaptation of nickel-chrome ( $\mathrm{Ni}-\mathrm{Cr}$ ) copings, cobaltchrome (Co-Cr) coping, and zirconium ( $\mathrm{Zr}$ ) copings, produced with different manufacturing procedures.

\section{Material and methods}

A total of 45 copings were fabricated on a standardized metal die by using a two-stage putty impression and poured with die stone. They were divided into three groups of 15 each: A, B, and C. For group A, Ni-Cr copings were fabricated by conventional casting procedures; for group B, Co-Cr copings by direct metal laser sintering (DMLS); and for group C, zirconium copings by computer-aided design and computer-aided manufacturing (CAD/CAM) systems. Four areas around the tooth surface, namely, the mid-mesial, buccal, distal, and lingual surfaces, were digitally analyzed for marginal adaptation under the scanning electron microscope.

\section{Results}

The mean marginal gap for group A on the mid mesial, buccal, distal, and lingual surfaces was 79.67, 83.27, 90.67 , and $89.13 \mu \mathrm{m}$, respectively. The mean marginal gap for group B on the mid-mesial, buccal, distal, and lingual surfaces was $38.13,46.20,45.73$, and $42.20 \mu \mathrm{m}$, respectively. The mean marginal gap for group C on the mid mesial, buccal, distal, and lingual surfaces was $36.73,31.73,29.00$, and $30.53 \mu \mathrm{m}$, respectively.

Received 10/29/2019

Review began 11/05/2019 Review ended 11/06/2019 Published 11/07/2019

\section{๑) Copyright 2019}

Doddy et al. This is an open access article distributed under the terms of the Creative Commons Attribution License CC-BY 3.0., which permits unrestricted use, distribution, and reproduction in any medium, provided the original author and source are credited.

\section{Conclusion}

The marginal adaptation of CAD/CAM Zr copings is more accurate when compared to the DMLS Co-Cr and Cast Ni-Cr copings on a standard master die.

Categories: Miscellaneous, Other, Dentistry

Keywords: marginal adaptation, scanning electron microscope

\section{Introduction}

Anterior and posterior teeth have been extensively restored, with single crown and bridges, for function, speech, comfort, and aesthetics. Casting alloys have been an important part of restorative dental treatment for more than a century. Restorations commonly fabricated for fixed prosthetic treatment, such as inlays, onlays, crowns, and fixed partial dentures, are fabricated in the dental laboratory using the lost wax technique introduced by Taggart in 1907 [1-2].

Marginal adaptation is critical for long-term longevity and the clinical success of dental restorations. Improper marginal adaptation may lead to oral fluids, resulting in microleakage and cement dissolution [36].

The poor internal fit of a coping can increase the thickness of the cement and thus influence the mechanical stability of dental restorations. Based on a literature review, the acceptable vertical marginal gap ranges between 10 and $160 \mu \mathrm{m}$ and the internal gap ranges between 81 and $136 \mu \mathrm{m}$ [7-8].

The purpose of this study was to compare and evaluate the marginal adaptation of cast Ni-Cr copings, DMLS Co-Cr copings, and CAD/CAM Zr copings. 


\section{Cureus}

\section{Materials And Methods}

\section{Methodology}

Fabrication of a Standardized Metal Die

In order to achieve standardized tooth preparation, a custom-made holding jig is fixed to a surveyor with a suspending arm, which was used to control the airotor orientation during tooth preparation. The movable table of the surveyor was adapted to secure the same angle of convergence for standard preparation (Figure 1). A uniform chamfer finish line of $0.5 \mathrm{~mm}$ in width, 6-degree occlusal convergence, $1.5 \mathrm{~mm}$ reduction on the functional cusp with functional cusp bevel, and $1 \mathrm{~mm}$ reduction on the non-functional cusp simulating a prepared mandibular first molar was scanned with a CAD/CAM machine (Sirona inEosX5; Sirona Dental Systems Inc., Long Island City, New York). The base of dimensions for the die was $15 \mathrm{~mm}$ x $14 \mathrm{~mm}$ x $5 \mathrm{~mm}$ (Figure 2). To fabricate a standard metal die by using CAD software data, which was then transferred to the $\mathrm{CAD} / \mathrm{CAN}$ milling machine (Sirona, inLab MC X5), and obtained the metal die (Co-Cr alloy). After finishing, the polishing of the master die was carried out.

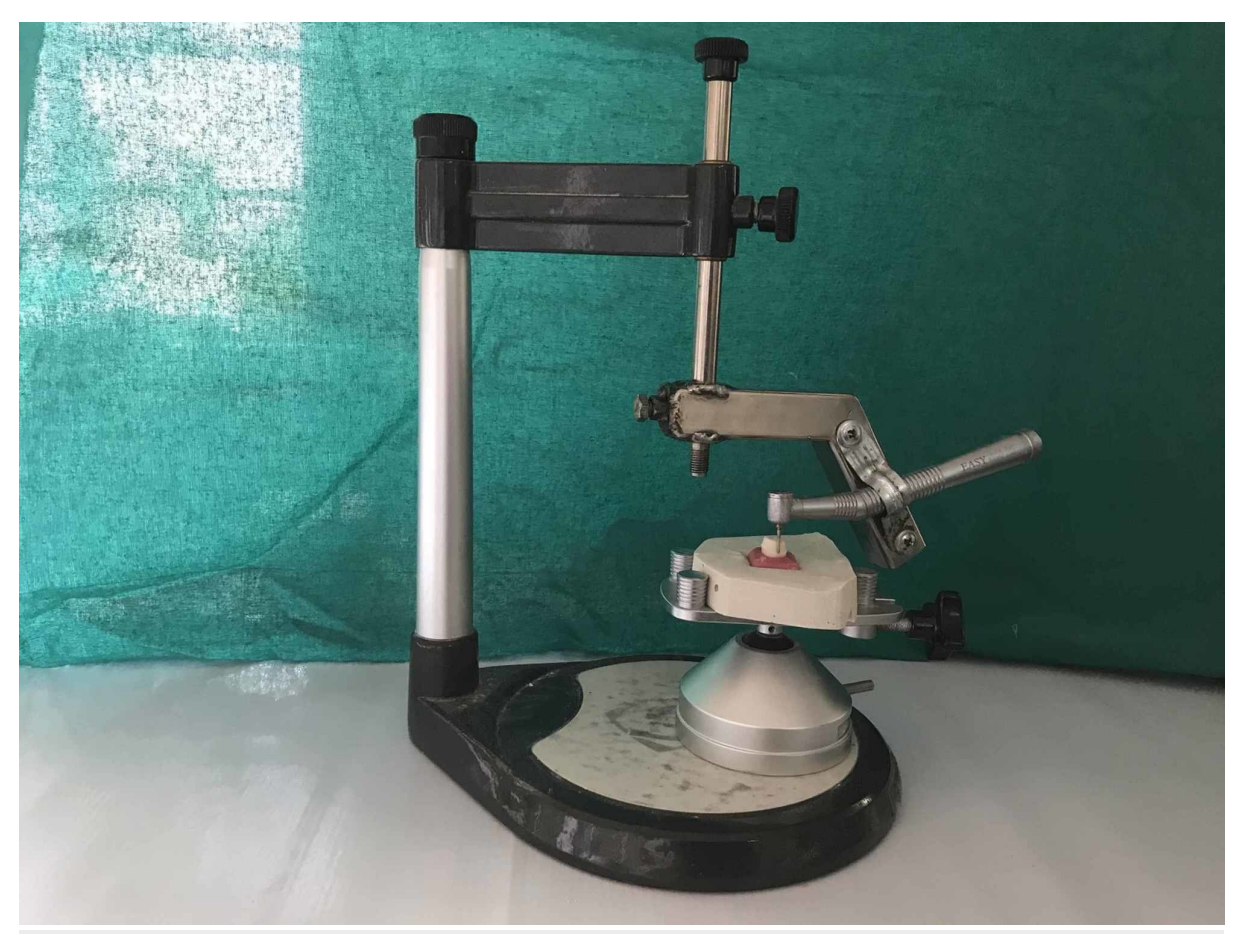

FIGURE 1: Tooth preparation on a dental surveyor 


\section{Cureus}

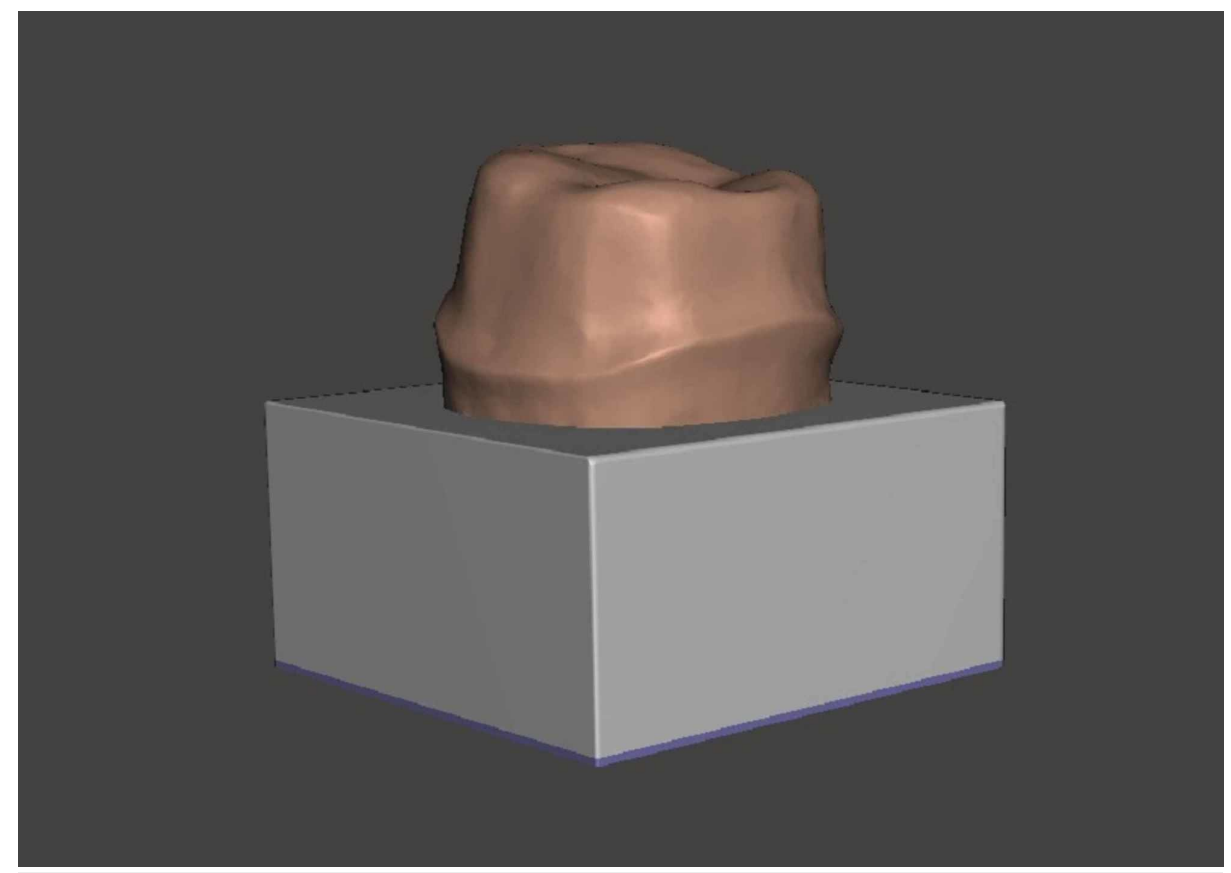

FIGURE 2: 3D scanned data

Fabrication of a Custom-made Tray and Two-stage Putty Impression

To standardize the impression of the metal die, a custom tray was fabricated in stainless steel (Figure 3). Holes were made on the outer surface of the square-shaped, stainless-steel custom tray for the mechanical retention of the impression material. Forty-five separate polyvinyl elastomeric siloxane impressions (Dentsply, Aquasil putty soft/light body, Germany) were made and the die stone (Type IV dental stone, Kalrock, Kalabhai Karson Pvt. Ltd., Mumbai, India) was mixed as per the manufacturer recommendation and poured into the mold using a mechanical vibrator.

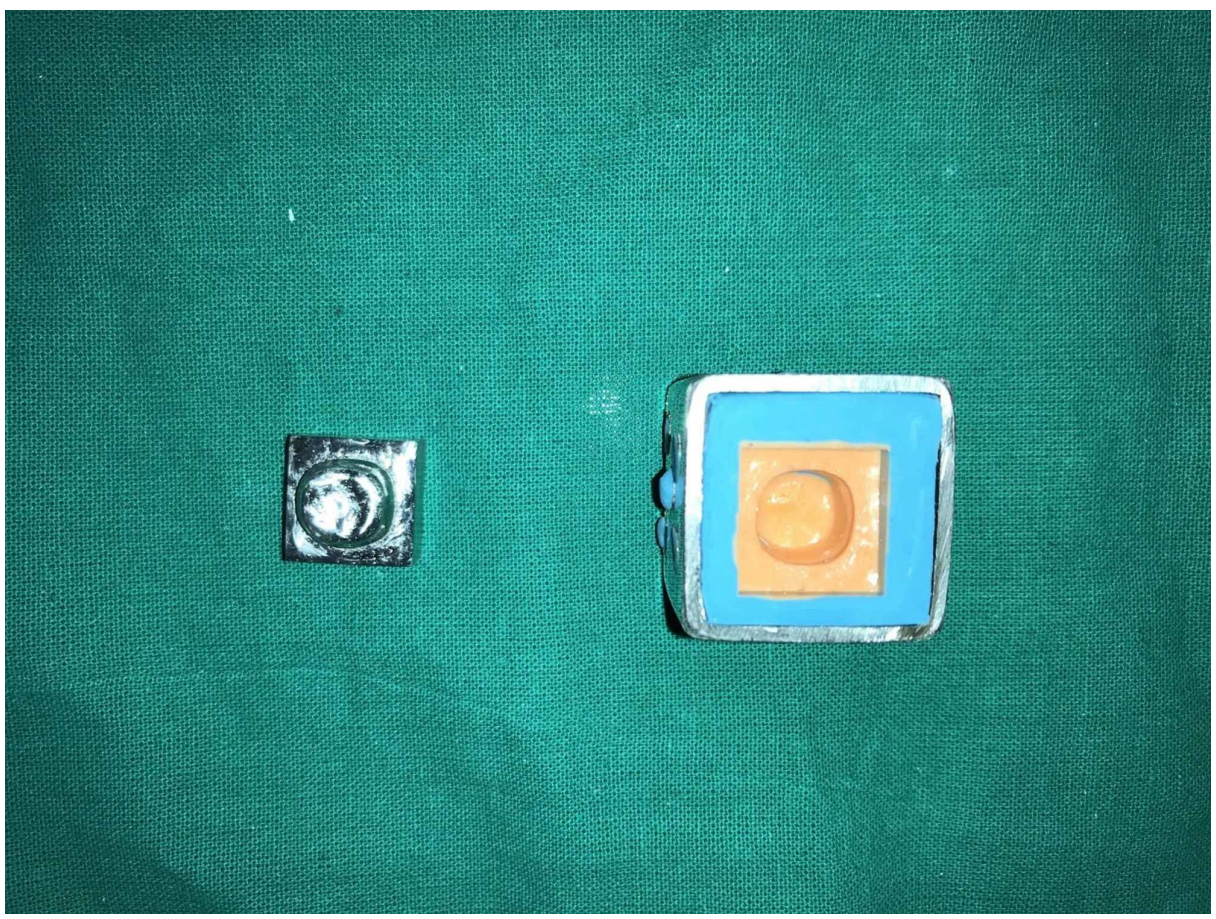

FIGURE 3: Metal die and two-stage putty impression

The working models were grouped as follows 


\section{Cureus}

1. Group A (Ni-Cr coping): Accelerated casting technique (15 samples)

2. Group B (Co-Cr coping): Direct metal laser sintering (15 samples)

3. Group C (Zirconium coping): CAD-CAM systems (15 samples)

\section{Fabrication of Groups $A, B$, and $C$ and Cementation}

To fabricate the cast Ni-Cr copings, the virtual wax pattern coping thickness should be designed as $0.5 \mathrm{~mm}$ using the CAD software program (Sirona, inEosX5). The wax pattern was invested with a phosphate-bonded investment (Bella Bond Plus, Bego Bremer Gold Wilh. Herbst GmbH \& Co. KG, Bremen, Germany) and cast with a Ni-Cr alloy (Bella Sun, Bego Bremer Gold Wilh. Herbst GmbH \& Co. KG) using a centrifugal casting machine (LC cast-60, Confident Dental Equipments Pvt. Ltd., New Delhi, India).

In order to fabricate the DMLS copings, the same virtual coping design was used, as stated above, with the CAD software program. Then, the copings were fabricated using a DMLS machine (EOSINT M270, EOS GmbH, Krailling, Germany) by fusing Co-Cr powder (EOS Cobalt Chrome SP2, EOS GmbH).

In order to fabricate zirconium copings, the same virtual coping design was used, as stated above, with the CAD software program. Designed data were converted into processing data and sent to the processing machine (inLab MC5, Sirona). The zirconia blocks (Cercon, Yttria-stabilized zirconia) were cut and milled, and then the milled blocks were finally sintered to make zirconia coping. After finishing and polishing, groups A, B, and C copings were evaluated for marginal adaptation (Figures 4-6).

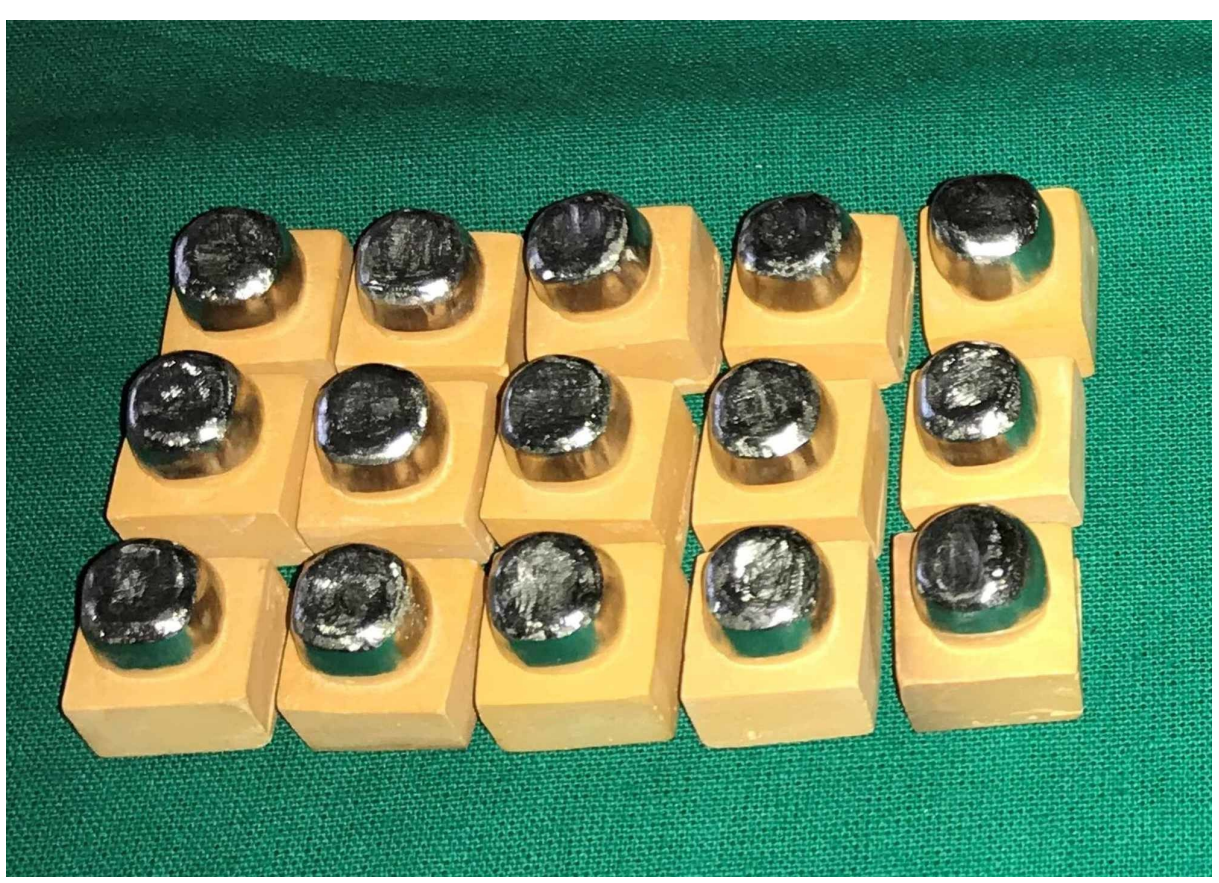

\section{FIGURE 4: Group A Ni-Cr copings}

Ni-Cr: nickel-chrome 


\section{Cureus}

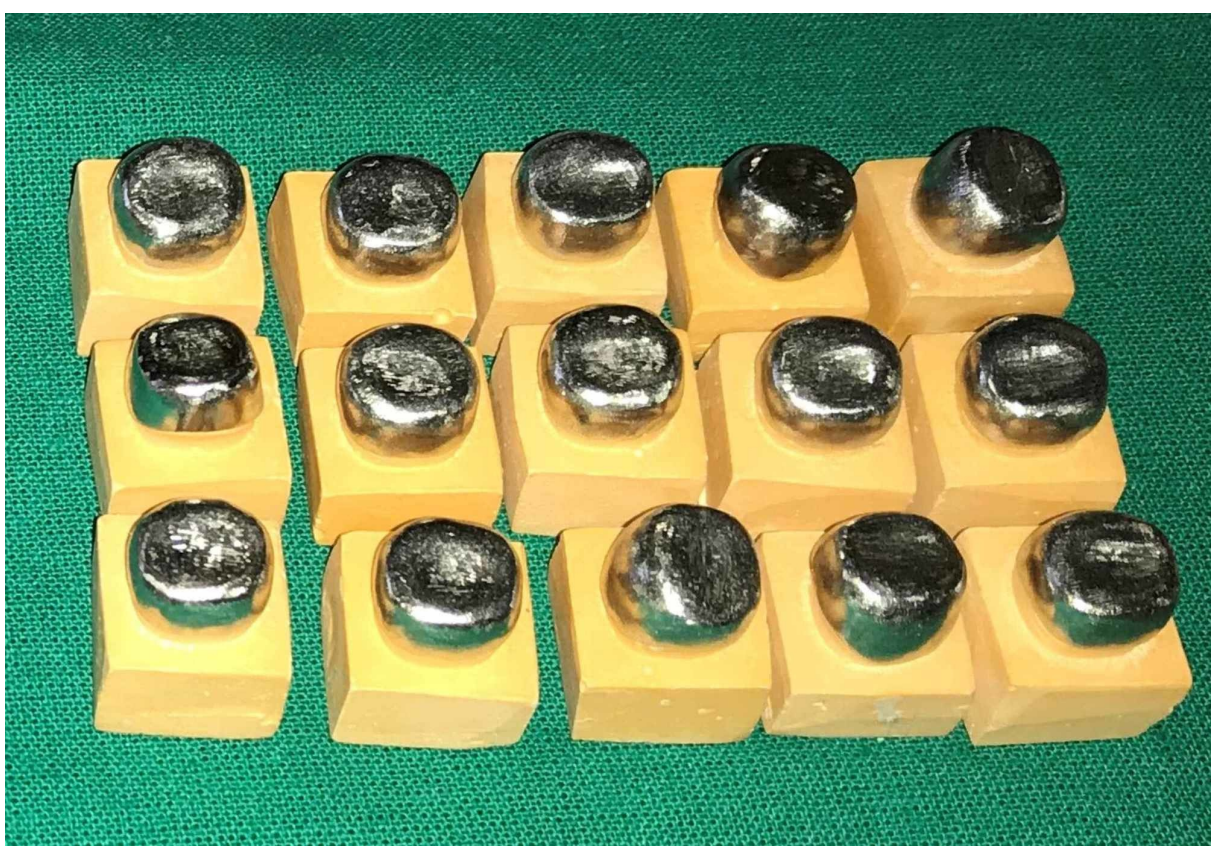

FIGURE 5: Group B Co-Cr coping

Co-Cr: cobalt-chrome

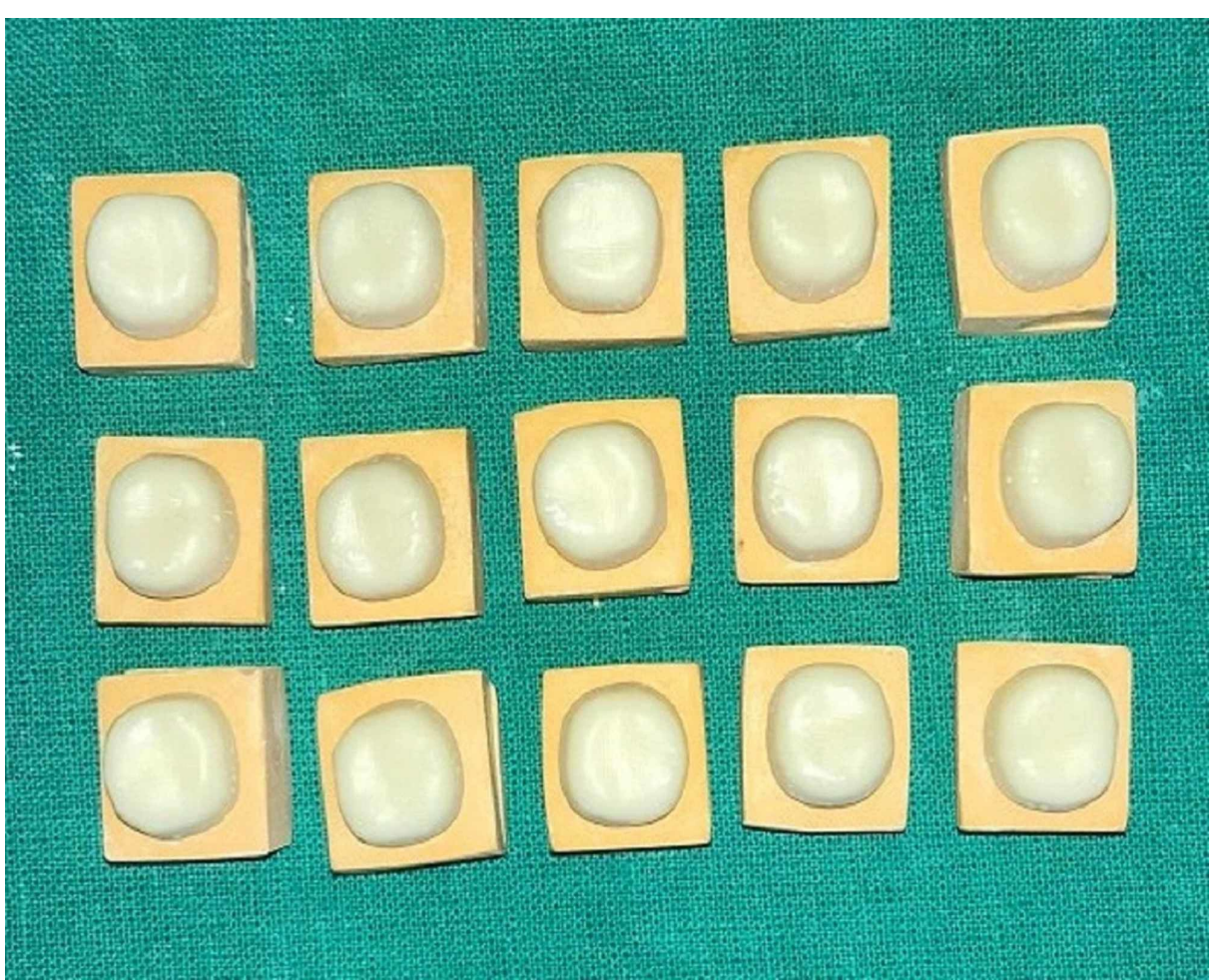

\section{FIGURE 6: Group C Zr coping}

Zr: zirconium

The 45 test samples were tried on the respective die stone models and inspected before the cementation procedure. A type I glass ionomer cement (GC Fuji, Tokyo, Japan) was used to lute the coping on the die (stone models), with the help of a finger until resistance was met. The excess cement was removed carefully and immediately, without damaging the margins of the die stone models. 


\section{Cureus}

Measurement of Vertical Marginal Adaptation Using a Scanning Electron Microscope

The samples were sputtered with gold for four minutes (DII-29030SCTR). After that, copings were placed in the scanning electron microscope (SEM) (JSM-IT500, JEOL, Ltd., Tokyo, Japan) at 200X magnifications using the particle measure system. Marginal adaptations were measured in four predetermined locations in the mid-mesial, mid-buccal, mid-lingual, and mid-distal surfaces of three groups of copings, respectively (Figures 7-9).

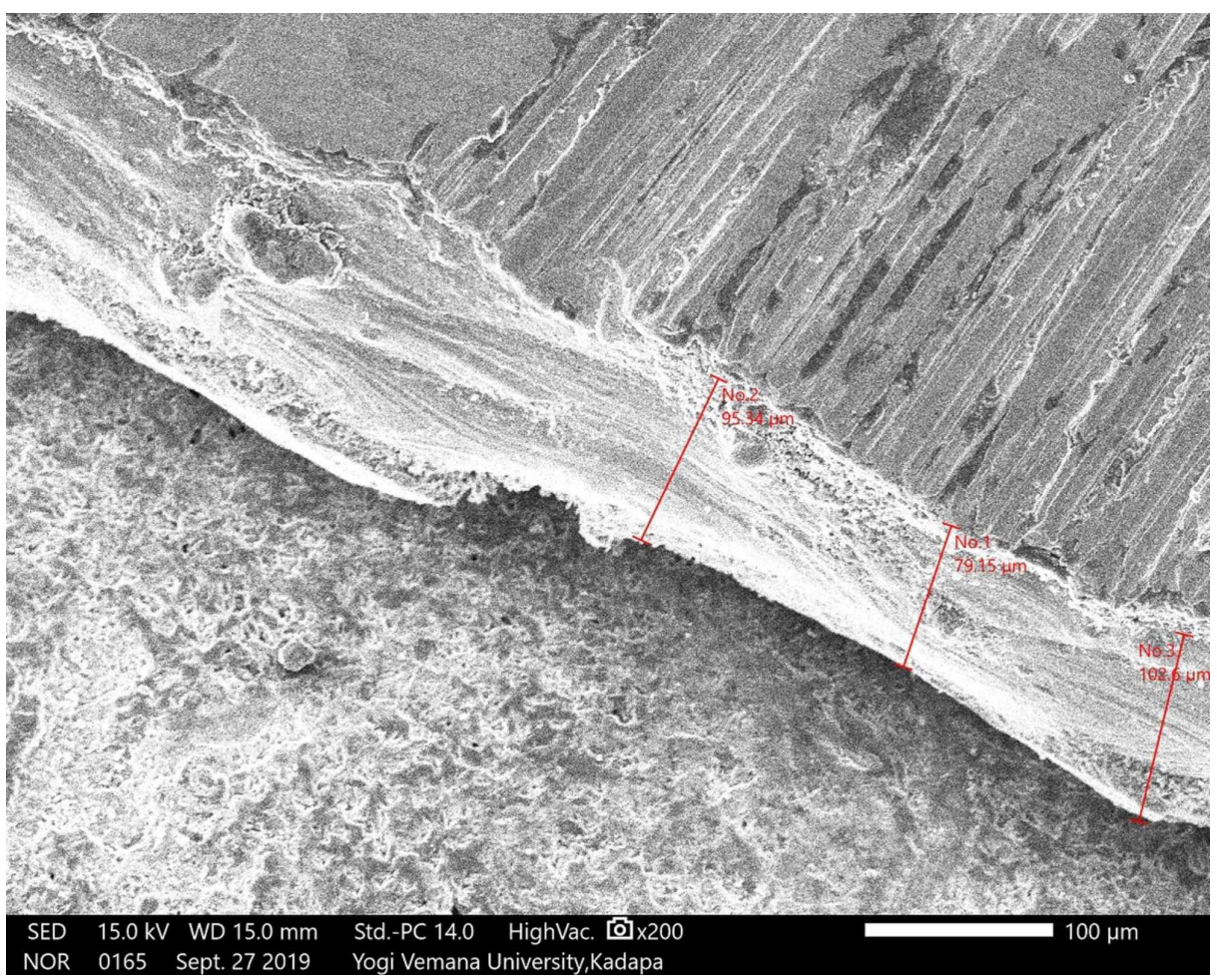

FIGURE 7: SEM analysis; group A Ni-Cr coping

SEM: scanning electron microscope; Ni-Cr: nickel-chrome

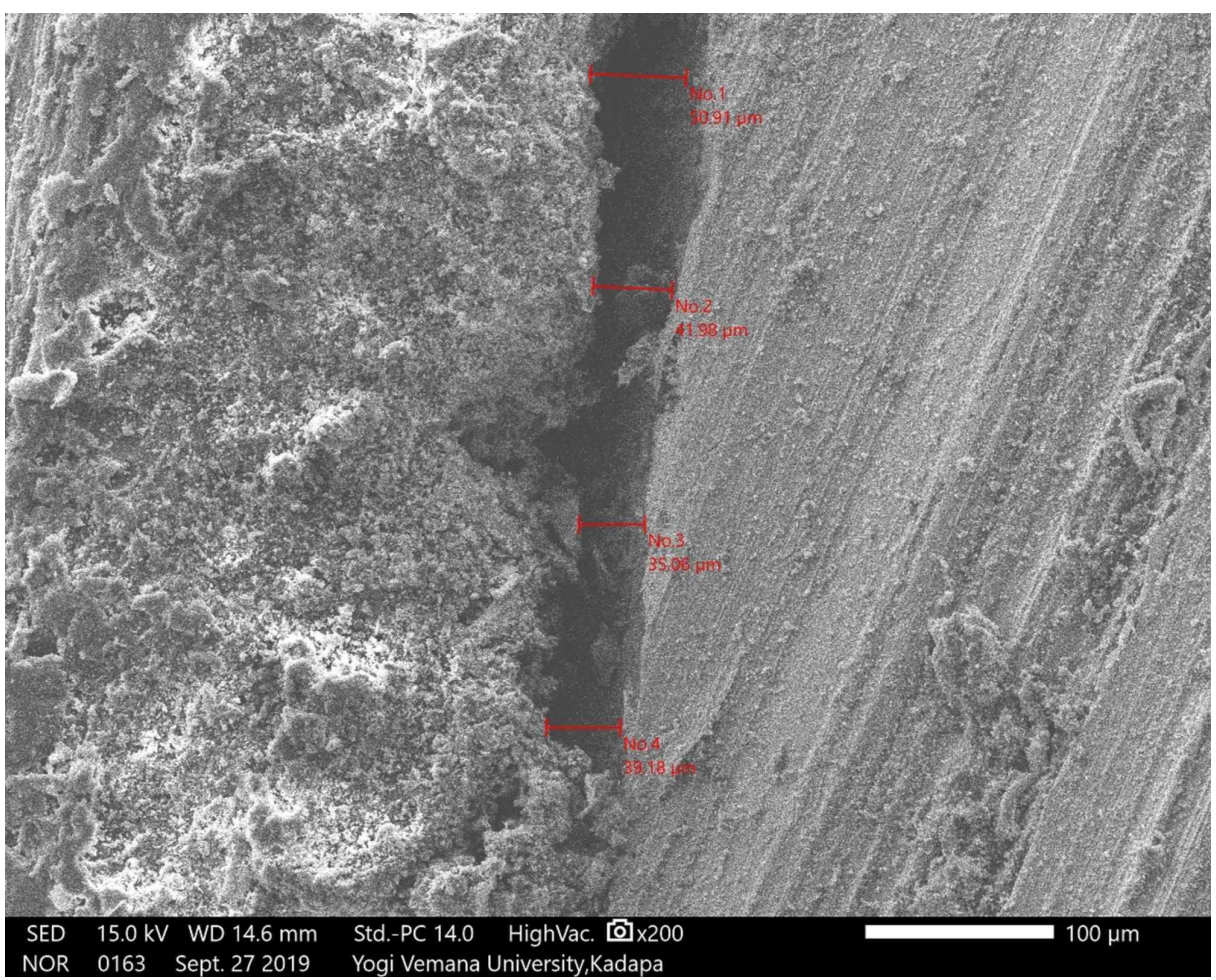




\section{Cureus}

FIGURE 8: SEM analysis; group B Co-Cr coping

SEM: scanning electron microscope; Co-Cr: cobalt-chrome

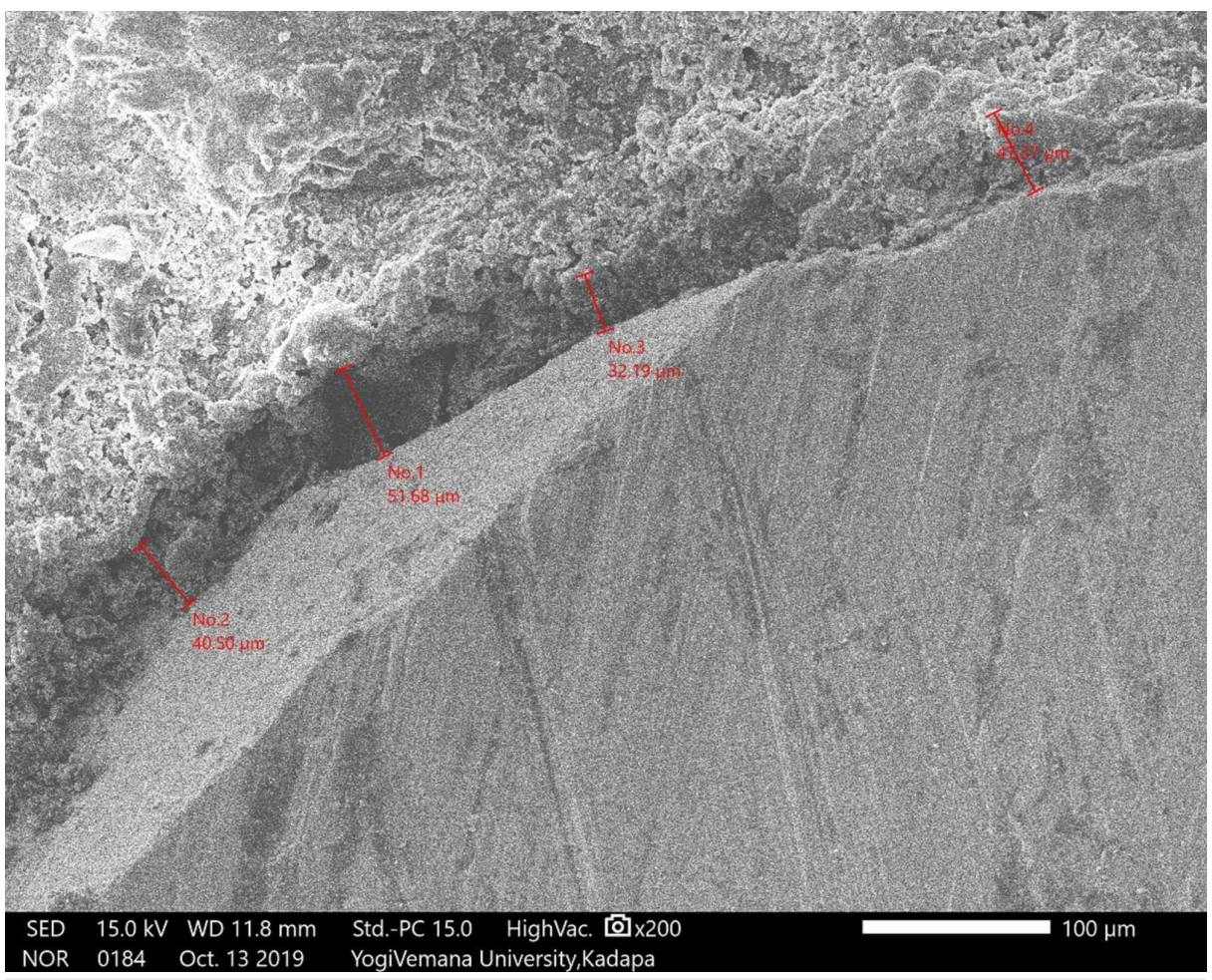

FIGURE 9: SEM analysis; group C Zr coping

SEM: scanning electron microscope; Zr: zirconium

\section{Results}

The mean \pm SD marginal gap of group A on the mid-mesial, buccal, distal, and lingual surfaces was $79.67 \pm$ $11.09,83.27 \pm 13.60,90.67 \pm 12.43,89.13 \pm 9.19 \mu \mathrm{m}$, respectively. The mean \pm SD marginal gap of group $B$ on the mid-mesial, buccal, distal, and lingual surfaces was $38.13 \pm 6.41,46.20 \pm 8.57,45.73 \pm 7.67,42.20 \pm 5.93$ $\mu \mathrm{m}$, respectively. The mean \pm SD marginal gap of group C on the mid-mesial, buccal, distal, and lingual surfaces was $36.73 \pm 9.06,31.73 \pm 14.02,29.00 \pm 7.10,30.53 \pm 9.93 \mu \mathrm{m}$, respectively (Table 1). A comparison of the three groups ( $\mathrm{Ni}-\mathrm{Cr}$ copings, $\mathrm{Co}-\mathrm{Cr}$ copings, and $\mathrm{Zr}$ copings) with the mean marginal gap in the midmesial, mid-buccal, mid-distal, and mid-lingual surfaces was done by one-way analysis of variance (ANOVA). The marginal adaptation of group A on the mid-mesial, buccal, distal, and lingual surfaces as compared to group $B$ and group $C$ was found to be statistically significant $(p<0.0001)$. The marginal adaptation of group B on the mid-mesial, buccal, distal, and lingual surfaces as compared to group $\mathrm{C}$ and group A was found to be statistically significant $(\mathrm{p}<0.0001)$. The marginal adaptation of group $C$ on the midmesial, buccal, distal, and lingual surfaces as compared to group A and group B was found to be statistically significant $(\mathrm{p}<0.0001)$. 


\section{Cureus}

\begin{tabular}{|c|c|c|c|c|c|c|}
\hline Variables & Groups A, B, C & Min & Max & Mean & SD & SE \\
\hline \multirow[t]{5}{*}{ Mid-mesial surface } & $\mathrm{Ni}$-Cr copings & 56.00 & 98.00 & 79.67 & 11.09 & 2.86 \\
\hline & Co-Cr copings & 29.00 & 51.00 & 38.13 & 6.41 & 1.66 \\
\hline & Zirconium copings & 25.00 & 51.00 & 36.73 & 9.06 & 2.34 \\
\hline & F-value & 108.786 & & & & \\
\hline & P-value & $0.0001^{*}$ & & & & \\
\hline \multirow[t]{5}{*}{ Mid-buccal surfaces } & $\mathrm{Ni}$-Cr copings & 59.00 & 102.00 & 83.27 & 13.60 & 3.51 \\
\hline & Co-Cr copings & 29.00 & 58.00 & 46.20 & 8.57 & 2.21 \\
\hline & Zirconium copings & 18.00 & 67.00 & 31.73 & 14.02 & 3.62 \\
\hline & F-value & 69.8692 & & & & \\
\hline & P-value & $0.0001^{*}$ & & & & \\
\hline \multirow[t]{5}{*}{ Mid-distal surfaces } & Ni-Cr copings & 67.00 & 112.00 & 90.67 & 12.43 & 3.21 \\
\hline & Co-Cr copings & 34.00 & 57.00 & 45.73 & 7.67 & 1.98 \\
\hline & Zirconium copings & 17.00 & 42.00 & 29.00 & 7.10 & 1.83 \\
\hline & F-value & 173.616 & & & & \\
\hline & P-value & $0.0001^{\star}$ & & & & \\
\hline \multirow[t]{5}{*}{ Mid- lingual surfaces } & $\mathrm{Ni}-\mathrm{Cr}$ copings & 67.00 & 102.00 & 89.13 & 9.19 & 2.37 \\
\hline & Co-Cr copings & 32.00 & 51.00 & 42.20 & 5.93 & 1.53 \\
\hline & Zirconium copings & 16.00 & 51.00 & 30.53 & 9.93 & 2.56 \\
\hline & F-value & 198.484 & & & & \\
\hline & P-value & $0.0001^{\star}$ & & & & \\
\hline
\end{tabular}

TABLE 1: Comparison of three groups (Ni-Cr copings, $\mathrm{Co}-\mathrm{Cr}$ copings, $\mathrm{Zr}$ copings) with a mean marginal gap in the mid-mesial, mid-buccal, mid-distal, and mid-lingual surfaces by one-way ANOVA

$\mathrm{Ni}-\mathrm{Cr}$ : nickel-chrome; Co-Cr: cobalt-chrome; Zr: zirconium; ANOVA: analysis of variance

\section{Discussion}

Marginal discrepancies in the range of 40-120 $\mu \mathrm{m}$ have been reported to be clinically acceptable with regards to the longevity of a restoration. All the copings tested in this study are in the range of $16-112 \mu \mathrm{m}$, which is within acceptable limits [7-11].

All the in-vitro studies were carried out with their standardized design. The method of measurement of marginal discrepancy was predominantly stereomicroscope or traveling microscope, and the optic microscope was used in their studies [11-16].

It is difficult to interpret the statistical results of previous studies because of variations in the sample size, measurements per specimens, and measurement methods used. The most common methods are direct viewing, sectioning, probing, and explorative and visual examinations. In the current study, the direct viewing of the crown on a die is used to measure the marginal fit of all the copings. Direct viewing has the advantage of being non-destructive and, therefore, applicable to clinical practice [17-19].

This in-vitro study examined the marginal adaptation of cast Ni-Cr copings, DMLS Co-Cr copings, and $\mathrm{CAD} / \mathrm{CAM} \mathrm{Zr}$ in predetermined areas, which was measured using an SEM. The marginal adaptation of CAD/CAM Zr copings is more accurate when compared to DMLS Co-Cr and Cast Ni-Cr copings on a standard master die. 


\section{Limitations}

This is an in-vitro study that cannot simulate oral conditions. Finger pressure has been used for the cementation procedure of the metal copings. Though this method simulates the cementation of restorations clinically, it should be emphasized that the use of finger pressure is variable.

\section{Conclusions}

The marginal fit of CAD/CAM zirconia copings is more accurate as compared to DMLS and cast $\mathrm{Ni}-\mathrm{Cr}$ alloy copings on a standardized metal master model. The base metal alloy (Ni-Cr) exhibited a discrepancy that was significantly higher than the rest of the groups. The marginal adaptation of all the copings was within the clinically acceptable range of $80-120 \mu \mathrm{m}$.

\section{Additional Information \\ Disclosures}

Human subjects: All authors have confirmed that this study did not involve human participants or tissue. Animal subjects: All authors have confirmed that this study did not involve animal subjects or tissue. Conflicts of interest: In compliance with the ICMJE uniform disclosure form, all authors declare the following: Payment/services info: All authors have declared that no financial support was received from any organization for the submitted work. Financial relationships: All authors have declared that they have no financial relationships at present or within the previous three years with any organizations that might have an interest in the submitted work. Other relationships: All authors have declared that there are no other relationships or activities that could appear to have influenced the submitted work.

\section{References}

1. Gardner FM: Margins of complete crowns-literature review. J Prosthet Dent. 1982, 48:396-400. 10.1016/0022-3913(82)90072-5

2. Holmes JR, Bayne SC, Holland GA, Sulik WD: Considerations in the measurement of marginal fit . J Prosthet Dent. 1989, 62:405-408. 10.1016/0022-3913(89)90170-4

3. Ushiwata O, de Moraes JV: Method for marginal measurement of restorations: an accessory device for toolmakers microscope. J Prosthet Dent. 2000, 83:362-366. 10.1016/S0022-3913(00)70141-7

4. Groten M, Axmann D, Prosbster L, Weber H: Determination of the minimum number of marginal gap measurements requirement for practical in vitro testing. J Prosthet Dent. 2000, 83:40-49. 10.1016/S00223913(00)70087-4

5. Riccitiello F, Amato M, Leone R, Spagnuolo G, Sorrentino R: In vitro evaluation of the marginal fit and internal adaptation of zirconia and lithium disilicate single crowns micro-CT comparison between different manufacturing procedures. Open Dent J. 2018, 12:160-172. 10.2174/1874210601812010160

6. Santosh YD, Nikhil R, Sumit JD, Mete JJ: In vitro comparison of marginal fit of cad-cam zirconia, SMLS CoCr, pressable lithium disilicate, and cast Ni-Cr copings. Adv Dent Oral Health. 2016, 2:555581.

7. Baig, MR, Tan, KB, Nicholls JI: Evaluation of the marginal fit of a zirconia ceramic computer-aided machined (CAM) crown system. J Prosthet Dent. 2010, 104:216-227. 10.1016/S0022-3913(10)60128-X

8. Karatasli O, Kursoglu P, Capa N, Kazazoglu E: Comparison of the marginal fit of different coping materials and designs produced by computer-aided manufacturing systems. Dent Mater J. 2011, 30:97-102. 10.4012/dmj.2010-063

9. Moldovan O, Luthardt RG, Corcodel N, Rudolph H: Three-dimensional fit of CAD/CAM-made zirconia copings. Dent Mater. 2011, 27:1273-1278. 10.1016/j.dental.2011.09.006

10. Grenade C, Mainjot A, Vanheusden A: Fit of single tooth zirconia copings: comparison between various manufacturing processes. J Prosthet Dent. 2011, 105:249-255. 10.1016/S0022-3913(11)60040-1

11. Chandrashekar S, Savadi RC, Dayalan M, Reddy GTP: A comparative evaluation of the marginal adaptation of zirconium coping and nickel-chromium coping using shoulder finish line design: an invitro study. J Indian Prosthodont Soc. 2012, 12:248-251. 10.1007/s13191-012-0175-0

12. Tamac E, Toksavul S, Toman M: Clinical marginal and internal adaptation of CAD/CAM milling, laser sintering, and cast metal-ceramic crowns. J Prosthet Dent. 2014, 112:909-913. 10.1016/j.prosdent.2013.12.020

13. Vaidya S, Parkash H, Bhargava A, Gupta S: Evaluation of the marginal fit of metal copings fabricated on three different marginal designs using conventional and accelerated casting techniques: an in vitro study. Indian J Dent Res. 2014, 25:641-647. 10.4103/0970-9290.147114

14. Gunsoy S, Ulusoy M: Evaluation of marginal/internal fit of chrome-cobalt crowns: direct laser metal sintering versus computer-aided design and computer-aided manufacturing. Niger J Clin Pract. 2016, 19:636-644. 10.4103/1119-3077.188699

15. Ullattuthodi S, Cherian KP, Anandkumar R, Nambiar MS: Marginal and internal fit of cobalt-chromium copings fabricated using the conventional and the direct metal laser sintering techniques: a comparative in vitro study. Indian Prosthodont Soc. 2017, 17:373-380. 10.4103/jips.jips_88_17

16. Quante K, Ludwig K, Kern M: Marginal and internal fit of metal-ceramic crowns fabricated with a new laser melting technology. Dent Mater. 2008, 24:1311-1315. 10.1016/j.dental.2008.02.011

17. Arora A, Yadav A, Upadhyaya V, Jain P, Verma M: Comparison of marginal and internal adaptation of copings fabricated from three different fabrication techniques: an in vitro study. J Indian Prosthodont Soc. 2018, 18:102-107. 10.4103/jips.jips_327_17

18. Ucar Y, Akova T, Akyil MS, Brantley WA: Internal fit evaluation of crowns prepared using a new dental crown fabrication technique: laser-sintered Co-Cr crowns. J Prosthet Dent. 2009, 102:253-259. 


\section{Cureus}

10.1016/S0022-3913(09)60165-7

19. Park JK, Lee WS, Kim HY, Kim WC, Kim JH: Accuracy evaluation of metal copings fabricated by computeraided milling and direct metal laser sintering systems. J Adv Prosthodont. 2015, 7:122-128.

10.4047/jap.2015.7.2.122 